\title{
Accessory parotid gland: its surgical importance
}

\author{
Mangalgiri $\mathbf{A}^{1}$, Mahore $\mathbf{D}^{2}$ \\ ${ }^{1}$ Dr. Ashutosh Mangalgiri, Professor, Department of Anatomy, Chirayu Medical College and Hospital, Bhopal, \\ ${ }^{2}$ Dr. Devendra Mahore, Professor \& Head, Department of ENT, Govt. Medical College, Chandrapur, Maharashtra, India.
}

Address for Correspondence: Dr. Devendra Mahore, Email: mahoredm@gmail.com

\begin{abstract}
Introduction: Accessory parotid gland is separated normal tissue from the main parotid gland, lying over the parotid duct. Accessory parotid gland is more prone for parotid tumors than main parotid gland. The accessory parotid is the site of congenital and acquired lesions. It usually presents as mid cheek swelling. Mid cheek incision may damage branches of facial nerve. Material \& Method: Forty parotid glands were dissected from 20 cadavers during a period of 2 years from 2014 to 2016. Dissections were carried out at Chirayu Medical College \& Hospital, Bhopal. Result: Out of 40 parotid glands dissected, accessory parotid glands were observed in 3 cases on right side. Incidence was found to be $7.5 \%$ for the present study. Accessory parotid gland was observed on right side lying on parotid duct detached from the main mass of the parotid gland. In case 2, accessory parotid was observed lying on parotid duct and here gland has two different ducts draining separately. Conclusion: Accessory parotid gland is the commonest site for pleomorphic adenoma. It may present as a slowly progressive mid cheek mass. They are more in accessory parotid than main mass of parotid gland. The accessory parotid not often mentioned variant is separate from main parotid gland should be addressed properly to ensure complete removal of disease. This is very important in malignancy for surgical clearance.
\end{abstract}

Keywords: Pleomorphic adenoma, Accessory parotid gland, Salivary glands, facial nerve, Parotid gland tumors

\section{Introduction}

The accessory parotid gland is a normal salivary tissue separate from the main parotid gland, over the masseter muscle and lying on or above the Stensen's duct (parotid duct), located on the masseter muscle and connected to the Stensen's duct at that level $[1,2,3]$. The accessory parotid is the site of congenital and acquired lesions. In adults, the acquired lesions are often neoplastic and are usually similar to those seen in the main parotid gland [4]. It may develop as a slowly progressive mid cheek mass. The incidence of parotid tumors is more common in accessory parotid gland than the main gland [5]. Accessory parotid gland lymphoma is a rare condition. Cases of presence of lymphoma from accessory parotid gland has been reported in literature $[2,6,7]$. Damage to the branches of facial nerve is reported following incision for removal of accessory parotid gland. Recovery from facial nerve paresis usually occurs in 6 months [3]. Presence of separate duct has also been reported arising from accessory parotid gland and emptying into main parotid duct [8].

\section{Materials \& Methods}

Dissection was carried out on 20 cadavers to find out the incidence of accessory parotid gland. Total 40 parotid glands were dissected from both sides of 20 cadavers. Cadaveric dissections were done at Chirayu Medical College \& Hospital, Bhopal. The study was conducted for a period of 2 years from 2014 to 2016.

\section{Result}

In 40 parotid gland dissections (20 right side and 20 left side), we found accessory parotid gland in 3 cadavers on right side. Incidence was found to be $7.5 \%$ for the present study. In case 1 (Figure 1) and case 3 (Figure 3 ) accessory parotid

\footnotetext{
Manuscript received $24^{\text {th }}$ August 2016

Reviewed: $10^{\text {th }}$ September 2016

Author Corrected: $20^{\text {th }}$ September 2016

Accepted for Publication $6^{\text {th }}$ October 2016
} 
gland was observed on right side lying on parotid duct detached from the main mass of the parotid gland. In case 2 , accessory parotid (Figure 2) was observed lying on parotid duct and here gland has two different ducts draining separately.

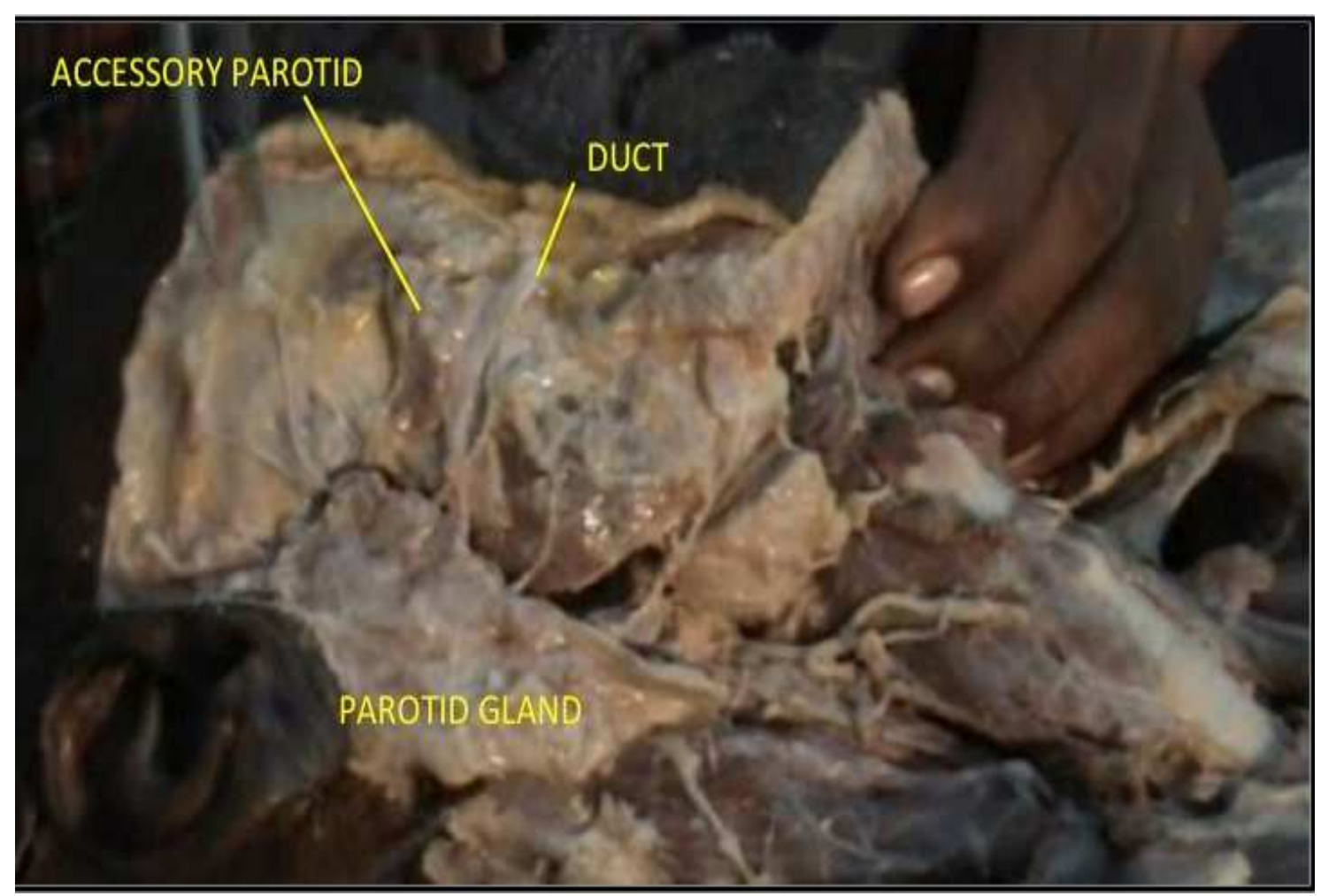

Fig-1: Showing accessory parotid above the stenson's duct separate from main parotid gland

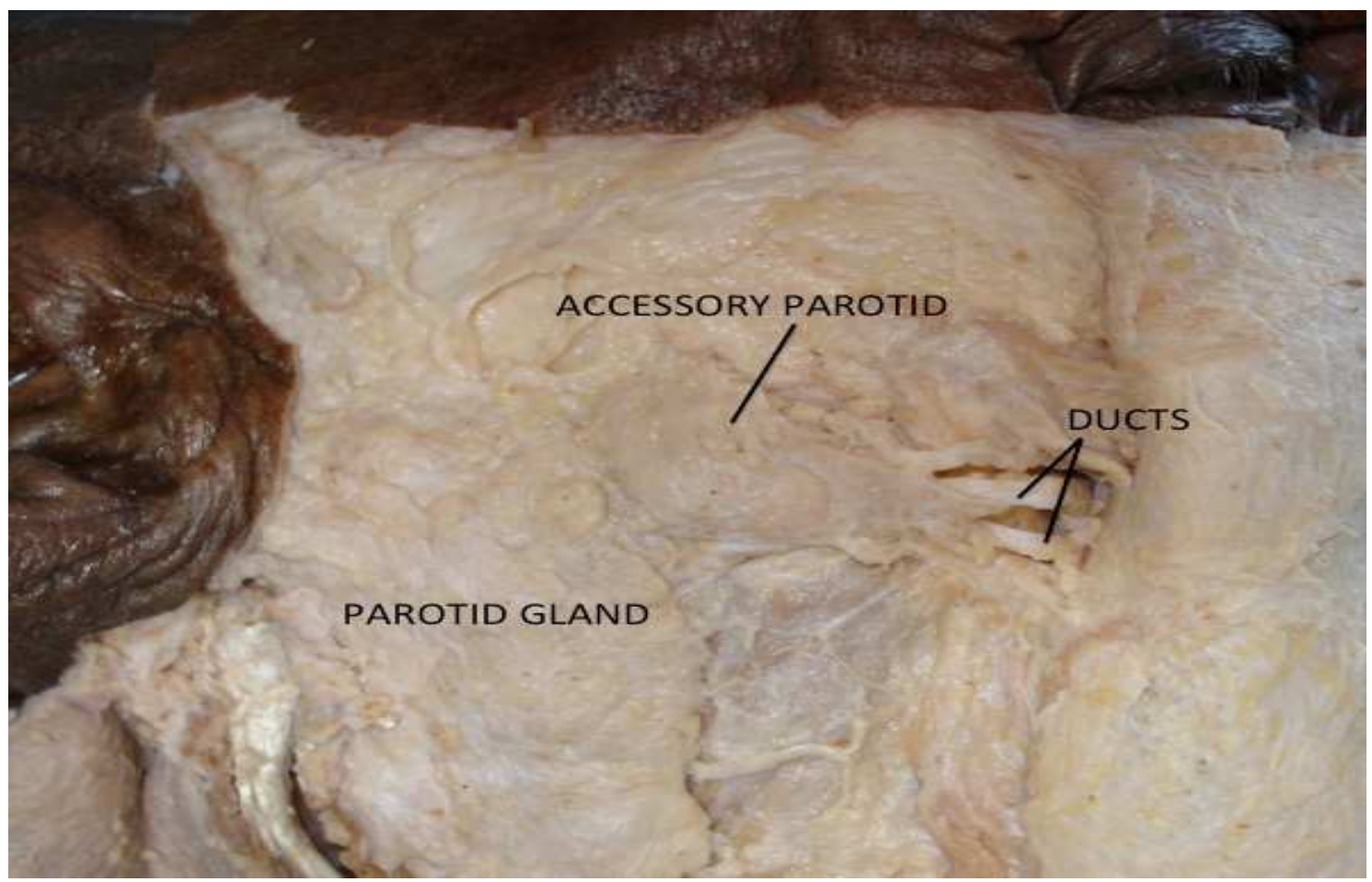

Fig-2: Showing accessory parotid, close to main parotid gland along with two separate ducts. 


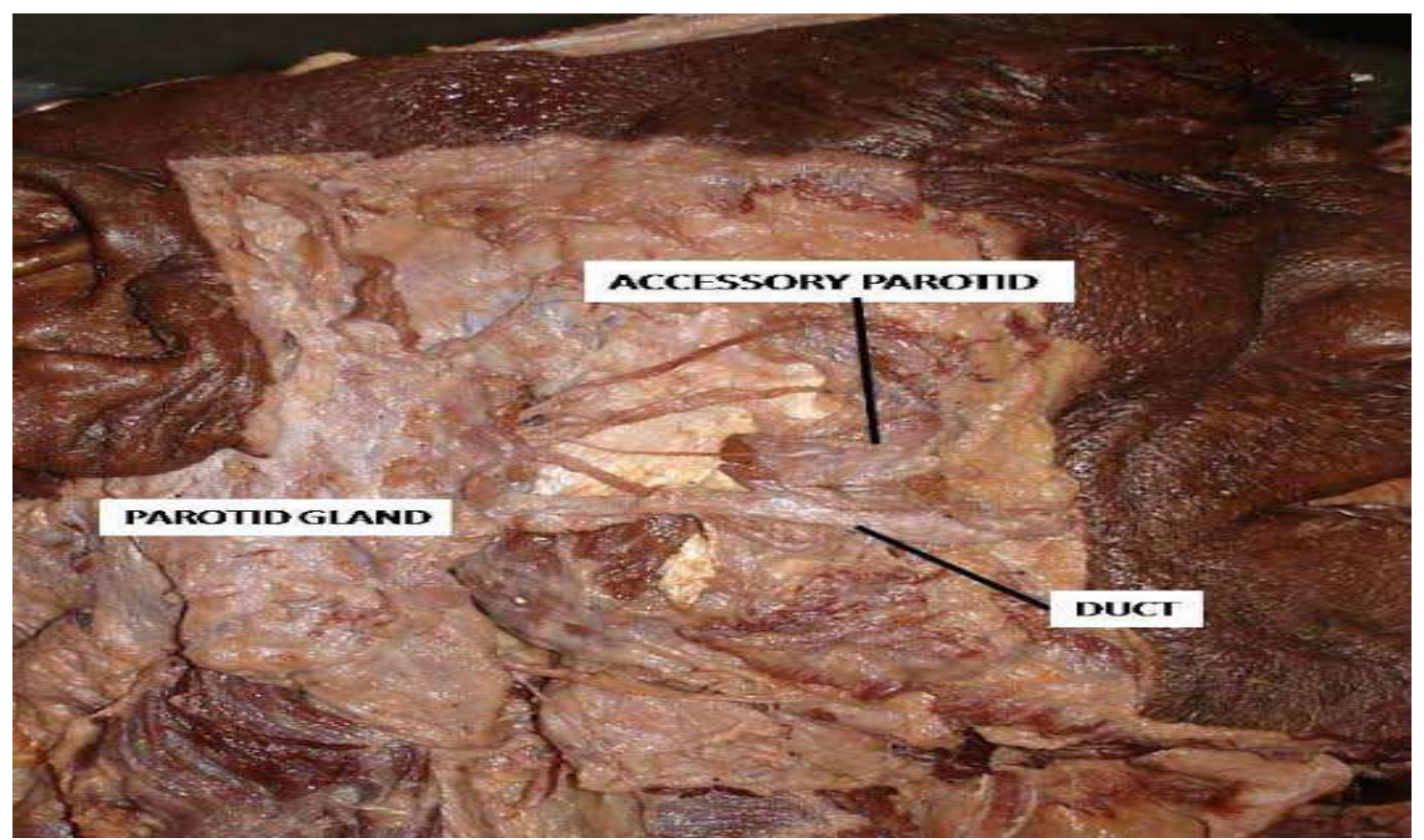

Fig-3: The third case showing distinct and separate accessory parotid

\section{Discussion}

The accessory parotid gland corresponds to the midpoint of an imaginary line extending from the tragus to a point midway between the ala of nose and the vermilion border of the upper lip [6]. Pleomorphic adenoma of parotid gland is the most common pathology and it is also known to have higher recurrence rate. The seedling of the tumor during surgical removal is said to be one of the reason for recurrence. Due to lack of anatomic barriers, extension of tumor shows significant soft tissue infiltration [9]. The accessory parotid is though separate from main gland is in close relation to it. One cannot rule out accessory parotid to be another cause for recurrence in case of non removal of accessory parotid gland.

The histological similarity of accessory gland and the main gland can be the reason that pathology of main gland could also involve accessory parotid. Figure 2, shows accessory parotid anterior and adjacent to the main parotid gland. Two separate ducts are also seen. In addition to the Stenson's duct, secondary duct was also identified emptying into main duct $[8,10]$. So it is advisable to look for and remove the accessory parotid in Malignancies.

Failure to identify and remove the accessory parotid during parotidectomy could be one of the cause for tumor recurrence. In present study the incidence of accessory parotid was $7.5 \%$ among 20 cadavers.
Accessory parotid incidence was found out in $20 \%$ of patients [3]. In a study of 228 cadaver dissections the incidence was found to be $56 \%$ [11]. In another study of 96 cadavers accessory parotid was present in $21 \%$ of cadavers [1]. Such significant incidence of accessory parotid suggests that during parotidectomy efforts should be made to identify accessory parotid, which will further reduce the chances of recurrence.

Frequency of malignancy is reported to be more in accessory parotid gland than main parotid gland [8]. Congenital fistula was also described from ectopic accessory parotid gland [12]. Surgical resection is the first choice of treatment and can be done by either cheek incision or modified Blair's incision [13]. One must be careful during exposure of the accessory parotid gland as facial nerve may get damaged during cheek incision [8].

\section{Conclusion}

The high incidence of accessory parotid suggests that it is mandatory to identify it and remove it during parotidectomy. This may help to reduce the recurrence rate. The identification and removal of accessory parotid is of surgical importance to ensure complete removal of disease.

\section{Funding: Nil, Conflict of interest: None.} Permission of IRB: Yes 


\section{References}

1. Frommer J. The human accessory parotid gland: its incidence, nature and significance. Oral Surg Oral Med Oral Pathol. 1977; 43(5): 671-6.

2. Fujimura K, Yoshida M, Sugimoto T et al. Two cases of non-Hodgkin's lymphoma in accessory parotid gland. Auris Nasus Larynx. 2004; 31:195-8.

3. Ramachar SM, Huliyappa HA. Accessory parotid gland tumors. Ann Maxillofac Surg. 2012 Jan; 2 (1): 90-3. doi: 10.4103/2231-0746.95334.

4. Currarino G, Votteler TP. Lesions of the accessory parotid gland in children. Pediatr Radiol. 2006 Jan;36(1):1-7; quiz 84-5. Epub 2005 Nov 12.

5. Perzik SL, White IL. Surgical management of preauricular tumors of the accessory parotid apparatus. Am J Surg. 1966 Oct;112(4):498-503.

6. Afify SE, Maynard JD. Tumours of the accessory lobe of the parotid gland. Postgrad Med J. 1992 Jun;68(800):461-2.

7. Urano M, Kiriyama $\mathrm{Y}$, Abe $\mathrm{M}$ et al. A case of mucosa associated lymphoid tissue (MALT) lymphoma arising in accessory parotid gland. Oral Med pathol. 2007;12:19-22.
8. Hamano T, Okami K, Sekine $\mathrm{M}$ et al. A case of accessory parotid gland tumor. Tokai J Exp Clin Med. 2004 Sep;29(3):131-3.

9. Tamiolakis D, Chimona TS, Geourgiou G, et al. Accessory parotid gland carcinoma ex pleomorphic adenoma. Case study diagnosed by fine needle aspiration. Stomatologija. 2009;11: 37-40.

10. Fernandes ACS, Lima GR, Rossi AM, Aguiar CM. parotid gland with double duct: An anatomic Variation Description. Int J Morphol. 2009; 27(1):129-32.

11. Toh H, kodama J, Fukuda J, Rittman B, Mackenzie I. Incidance and histology of human accessory parotid glands. Anatomical Record. 1993;236:586-90.

12. Moon WK, Han MH, Kim IO, Sung MW, Chang $\mathrm{KH}$, Choo SW, Han MC. Congenital fistula from ectopic accessory parotid gland: Diagnosis with CT sialography and CT fistulography. 1995; AJNR; 16: 997-9.

13. Rodino W, Shaha AR. Surgical management of accessory parotid tumors. J surg Oncol. 1993;54:153-6.

\section{How to cite this article?}

Mangalgiri A, Mahore D. Accessory parotid gland: its surgical importance. Int J Med Res Rev 2016;4(10):19031906.doi:10.17511/ijmrr. 2016.i10.29. 